\title{
PERANAN NELAYAN TERHADAP REHABILITASI EKOSISTEM HUTAN BAKAU (MANGROVE)
}

\author{
Otniel Pontoh ${ }^{1}$
}

\begin{abstract}
Mangrove forest ecosystem has an important role for the welfare of the fishermen, because the daily activities of fishing is always related to the mangrove ecosystem. Therefore, it is necessary to make an effort to restore degraded mangrove forest in order to return to their function for human welfare, especially fishermen, and support the development of coastal areas. The participation in rehabilitation and managing of mangrove ecosystem is the key to the success of mangrove conservation. The level of knowledge and the role of fishermen on the mangrove ecosystem rehabilitation will be discussed in this paper.
\end{abstract}

Keywords: Fishermen, Rehabilitation, Mangrove Forest.

\begin{abstract}
ABSTRAK
Ekosistem hutan mangrove memiliki peran yang sangat penting bagi kehidupan nelayan, karena aktifitas sehari-hari nelayan selalu berhubungan langsung dengan ekosistem hutan bakau. Oleh karena itu, perlu dilakukan berbagai upaya untuk memulihkan kembali hutan bakau yang rusak agar dapat kembali memberikan fungsinya bagi kesejahteraan manusia khususnya nelayan dan mendukung pembangunan wilayah pesisir. Keikutsertaan nelayan dalam upaya rehabilitasi dan pengelolaan bakau dapat menjadi kunci keberhasilan pelestarian bakau. Tingkat pengetahuan dan respon nelayan terhadap rahabilitasi ekosistim hutan manggrove akan didiskusikan dibawah ini.
\end{abstract}

Kata kunci: Nelayan, Rehabilitasi, Hutan Bakau.

${ }^{1}$ Staf pengajar Fakultas Perikanan dan IImu Kelautan Universitas Sam Ratulangi

\section{PENDAHULUAN}

\section{Latar Belakang}

Fungsi hutan bakau di wilayah pesisir bukan hanya penting sebagai pelindung fisik tetapi juga sebagai bagian terintegrasi dari eksositem wilayah pesisir lainnya, seperti ekosistem terumbu karang dan ekosistem padang lamun. Di Sulawesi Utara, hutan bakau sebagian besar telah rusak karena dikonversi menjadi lahan tambak dan pemukiman. Selain itu, pengambilan kayu bakau oleh masyarakat sekitar, untuk dijadikan kayu bakar merupakan penyebab lain kerusakan hutan bakau. Dengan demikian, berbagai aktivitas manusia memberi dampak pada kerusakan bakau.

Usaha rehabilitasi hutan bakau di beberapa daerah, baik di pulau Jawa, Sumatra, Sulawesi, maupun Irian Jaya telah berulangkali dilakukan, namun hasil yang diperoleh relatif tidak sesuai dengan biaya dan tenaga yang dikeluarkan oleh pemerintah. Salah satu penyebabnya adalah kurang keterlibatan dan peran serta masyarakat dalam pengembangan wilayah, khususnya rehabilitasi hutan bakau; dan masyarakat masih cenderung dijadikan obyek dan bukan subyek dalam upaya pembangunan (Subing, 1995).

Rehabilitasi hutan bakau merupakan langkah perlindungan yang ramah lingkungan. Pelibatan masyarakat dalam kegiatan rehabilitasi atau perbaikan ekosistem bakau penting untuk menumbuhkan rasa memiliki dan rasa tanggung jawab dalam menjaga sumberdaya alam di sekitar tempat tinggalnya. Pelibatan masyarakat dalam melestarikan hutan bakau ini perlu dimulai dari pelatihan mengenai teknik-teknik rehabilitasi untuk mendukung program konservasi hutan bakau.

Dengan demikian semua proses rehabilitasi dan reboisasi hutan bakau yang 
dimulai dari proses penanaman, perawatan, penyulaman tersebut dilakukan oleh masyarakat. Melalui mekanisme ini, masyarakat tidak merasa dianggap sebagai pekerja melainkan ada rasa kepemilikan terhadap hutan bakau tersebut, karena mereka merasa ikut punya andil dalam perencanaan penanaman dan lain-lain, sehingga status mereka akan berubah, yaitu bukan sebagai kuli lagi melainkan pemilik.

Ekosistem hutan bakau memiliki fungsi ekologis dan ekonomis yang penting dalam pembangunan, khususnya di wilayah pesisir. Meskipun demikian, kondisi hutan bakau di Indonesia terus mengalami kerusakan dan pengurangan luas lahan dengan kecepatan kerusakan mencapai 530.000 ha/tahun. Sementara laju penambahan luas areal rehabilitasi bakau yang dapat terealisasi masih jauh lebih lambat dibandingkan dengan laju kerusakannya, yaitu hanya sekitar 1.973 ha/tahun atau 0,4\%/tahun dari total kecepatan kerusakan hutan bakau.

Di Sulawesi Utara, bakau tumbuh hampir di sepanjang pantai Molas, Wori serta pantai Utara dan Timur Kecamatan Likupang. Taman Nasional Bunaken (TNB) memiliki luas total sekitar $1.800 \mathrm{Ha}$ yaitu $20 \%$ terdiri dari hutan bakau dengan rincian mengelilingi pulau Mantehage $( \pm 1.435 \mathrm{Ha})$, pulau Bunaken $( \pm 75 \mathrm{Ha})$, pulau Manado Tua $( \pm 7,7 \mathrm{Ha})$, Pulau siladen dan pulau Nain $( \pm 7 \mathrm{Ha})$. Di pesisir bagian utara Malalayang dan Wori $235 \mathrm{Ha}$ dan Arakan Wawontulap seluas $933 \mathrm{Ha}$ (Anonimous, 2005).

Hutan bakau Desa Tiwoho Kecamatan Wori Kabupaten Minahasa Utara memiliki luas $62,5 \mathrm{Ha}$. Oleh karena itu, perlu dilakukan berbagai upaya untuk memulihkan kembali hutan bakau yang rusak agar dapat kembali memberikan fungsinya bagi kesejahteraan manusia dan mendukung pembangunan wilayah pesisir. Keikutsertaan masyarakat dalam upaya merehabilitasi dan pengelolaan bakau dapat menjadi kunci keberhasilan pelestarian bakau. Terutama nelayan, dimana nelayan dalam aktifitas sehari-hari berhubungan langsung dengan ekosistem hutan bakau. Jadi nelayanlah yang secara langsung merasakan manfaat dari ekosistem hutan bakau. Untuk itu, kegiatan pemberdayaan masyarakat pesisir melalui kajian pengetahuan nelayan dan bagaimana respon nelayan terhadap rehabilitasi ekosistem hutan bakau.

\section{Tujuan Penelitian}

Penelitian ini bertujuan mengkaji tingkat pengetahuan dan respon nelayan terhadap rehabilitasi ekosistem hutan bakau, yang mengambil lokasi penelitian Desa Tiwoho Kecamatan Wori Kabupaten Minahasa Utara. Propinsi Sulawesi Utara.

\section{METODE PENELITIAN}

Penelitian ini menggunakan studi kasus. Data yang dikumpulkan dengan metode sensus, melalui teknik penarikan data dengan mengambil seluruh anggota populasi sebagai responden. Hal ini memungkinkan data yang lengkap karena mencerminkan sifat-sifat seluruh populasi

Data yang dikumpulkan terdiri dari data primer dan data sekunder. Data primer diperoleh langsung di lokasi penelitian dengan cara wawancara dan observasi yang terencana (pedoman kuesioner). Observasi dimaksudkan untuk memperoleh gambaran tentang lokasi penelitian, keadaan lingkungan, ekosistem bakau dan kegiatan yang dilakukan masyarakat dan pemerintah yang terkait dalam pengelolaan ekosistem bakau. Data sekunder diperoleh dari literatur serta bahan bacaan dan lembaga atau institusi terkait dalam penelitian ini (Singarimbun, M. dan S. Effendi, 1989).

Analisa data yang dilakukan dengan metode deskriptif kualitatif dan deskripsi kuantitatif. Analisa deskriptif kualitatif adalah pengolahan data yang dilakukan melalui beberapa pertimbangan logika dengan bahasa penulis yang sistematis, sedangkan analisa data kuantitatif merupakan pengolahan data dengan mengunakan perhitungan matematis sederhana seperti penjumlahan, persentase, angka rata-rata dan sebagainya (Kartono, 2000).

Skala Likert digunakan untuk mengukur sikap, pendapat dan persepsi seseorang atau sekelompok orang tentang fenomena sosial. Dengan skala ini, variabel yang akan diukur dijabarkan menjadi indikator variabel. Kemudian indikator tersebut dijadikan sebagai titik tolak untuk menyusun item-item instrumen yang dapat berupa pertanyaan atau pernyataan. Jawaban seti- 
ap item mempunyai gradasi dari sangat positif sampai sangat negatif, yang dapat berupa kata-kata sebagai contoh antara lain sangat berperan, berperan, cukup berperan, tidak terlalu berperan dan sangat tidak berperan. Untuk penilaian manfaat ekosistem bakau, maka jawaban itu dapat diberi skor, misalnya:
a. Sangat Berperan
b. Berperan
c. Cukup Berperan
d. Tidak Terlalu Berperan
e. Sangat Tidak Berperan

Instrumen ini dapat dibuat dalam bentuk checklist ataupun pilihan ganda. Data yang telah dianalisa dengan skala Likert kemudian dihitung korelasi antara setiap pernyataan dengan skor total dengan menggunakan rumus korelasi Product Moment yaitu teknik korelasi tunggal yang digunakan untuk mencari koefisien korelasi antara data interval satu dengan lainnya.

\section{HASIL DAN PEMBAHASAN}

\section{Keadaan Umum Desa}

Desa Tiwoho termasuk dalam wilayah kecamatan Wori, Kabupaten Minahasa Utara, Provinsi Sulawesi Utara. Jumlah penduduk sebanyak 1.116 jiwa dengan mata pencarian sebagian besar adalah petani $(38 \%)$ dan nelayan $(16 \%)$. Tingkat pendidikan masyarakat pada umumnya sekolah dasar dengan nilai persentasenya $63,3 \%$ dan yang tidak mengecap pendidikan sebanyak 2 (dua) orang atau $6,7 \%$. Jenjang pendidikan yang lebih tinggi seperti sekolah menengah umum maupun perguruan tinggi sulit dijangkau karena terbentur dengan keterbatasan ekonomi. Selain itu, tidak adanya sarana pendidikan lanjut di desa Tiwoho menjadi penghambat karena semakin jauh sekolah semakin menambah biaya sekolah.

Posisi desa mempunyai ketinggian 0-100 meter dari permukaan laut dan memiliki kondisi permukaan tanah berpasir yang datar dan berbukit. Pemukiman dan garis pantai dibatasi oleh tanggul sepanjang $\pm 200 \mathrm{~m}$ dan bakau. Luas wilayah desa adalah $556.485 \mathrm{Ha}$ dengan hutan bakau $62,5 \mathrm{Ha}(11,2 \%)$.

\section{Sejarah Rehabilitasi Hutan Bakau}

Sejak dahulu masyarakat Tiwoho terbiasa memanfaatkan hutan bakau sebagai sumber penghidupan, diantaranya: tempat mencari kayu bakar, bahan baku pembuatan atap rumah, sumber obat-obatan tradisional, tempat mencari ikan, katang (kepiting), biak (kerang) dan hewan buruan lainnya. Kebiasaan ini telah berlangsung turun-temurun hingga pada suatu ketika di akhir 1989 sebuah perusahaan bernama Wori Mas membuat usaha tambak udang dan bandeng. Sekitar 25 hektar hutan bakau dikonversi menjadi kolam-kolam pembudidayaan udang dan bandeng. Akibatnya berkurangnya jumlah ikan, kerang dan kepiting karena kehilangan tempat bertelur dan memijah, tidak adanya penahan ombak dan angin. Pada tahun 1991 pemerintah melalui Departemen Kehutanan menetapkan wilayah hutan bakau Desa Tiwoho masuk ke dalam wilayah Taman Nasional Bunaken (TNB). Sebagai tindak-lanjutnya penanaman bakau dilakukan pada bagian garis pantai untuk menghindari terjadinya abrasi. Jenis bakau setempat yang ditanam adalah Sonneratia sp. dan Avicennia alba dengan mengambil benih dari sekitar hutan bakau yang masih sehat. Penanaman bakau terkonsentrasi pada lahan bekas tambak. Sampai saat ini masyarakat yang bekerjasama dengan yayasan KELOLA masih melakukan penanaman bakau.

\section{Peran Kelembagaan}

\section{Pemerintah}

Mengacu pada PERDA SULUT No 38 tahun 2003 tentang pengelolaan wilayah pesisir dan laut terpadu berbasis masyarakat dalam pasal 14, masyarakat lokal dalam hal ini pemerintah desa berkewajiban menyusun peraturan desa untuk menjaga dan mempertahankan objek-objek yang bernilai ekonomi dan bernilai ekologis dari lingkungan hidup sumberdaya wilayah pesisir dan laut, juga memberikan informasi yang diperlukan dalam pengelolaan sumberdaya wilayah pesisir yang bertujuan untuk meningkatkan kualitas hidup masyarakat lokal.

Hasil penelitian dimana peran serta pemerintah daerah terhadap rehabilitas ekosistem bakau dapat dilihat pada tabel 1 berikut ini. 
Tabel 1. Peran serta pemerintah daerah terhadap rehabilitas ekosistem bakau.

\begin{tabular}{|c|c|c|c|c|}
\hline No & $\begin{array}{c}\text { Peran } \\
\text { Pemerintah }\end{array}$ & Skor & $\begin{array}{l}\text { Pernyataan } \\
\text { Responden }\end{array}$ & $\begin{array}{c}\text { Persentase } \\
(\%)\end{array}$ \\
\hline 1 & $\begin{array}{l}\text { Sangat } \\
\text { Berperan }\end{array}$ & 5 & 0 & 0 \\
\hline 2 & Berperan & 4 & 0 & 0 \\
\hline 3 & $\begin{array}{l}\text { Cukup } \\
\text { Berperan }\end{array}$ & 3 & 11 & 36,67 \\
\hline 4 & $\begin{array}{l}\text { Tidak Terlalu } \\
\text { Berperan }\end{array}$ & 2 & 19 & 63,33 \\
\hline \multirow[t]{2}{*}{5} & $\begin{array}{l}\text { Tidak } \\
\text { Berperan }\end{array}$ & 1 & 0 & 0 \\
\hline & & Total & 30 & 100,00 \\
\hline
\end{tabular}

Dalam Tabel di atas menunjukan hal bahwa perhatian pemerintah daerah masih sangat kurang dalam rehabilitasi hutan bakau, dimana sebesar $63,33 \%$ menyatakan bahwa pemerintah tidak terlalu berperan. Pada jawaban no 3 (tiga) dimana menurut masyarakat, pemerintah hanya Cukup Berperan sebesar $36,67 \%$.

Berdasarkan hasil analisis teknik korelasi Product Moment didapat hasil 0,428 (pernyataan 1), jika dibandingkan dengan angka kritik tabel korelasi nilai -r maka pernyataan ini memiliki validitas konstruk, artinya pernyataan ini memiliki hubungan korelasi dengan pernyataan yang lain.

Hasil penelitian di lapangan, masyarakat desa Tiwoho juga mengeluhkan keterlibatan pemerintah daerah dalam hal pelestarian bakau. Selama ini pemerintah daerah hanya sekali terlibat langsung dalam rehabilitasi hutan bakau. Selain itu juga bibit yang mereka tanam hampir seluruhnya mati. Hal ini disebabkan ketidakcocokan bibit dengan lahan yang ditanami. Sementara itu, pemerintah desa yang menjadi perpanjangan tangan pemerintah pusat dan daerah belum membuat peraturan desa yang secara tertulis dalam hal pengelolaan dan pemanfaatan ekosistem bakau.

\section{Lembaga Swadaya Masyarakat}

Lembaga swadaya masyarakat (LSM) atau NGO (Non-Governmental Organization) memiliki peran yang sangat besar dalam rehabilitasi hutan bakau.

Adapun hasil penelitian, peran serta LSM terhadap rehabilitas ekosistem bakau dapat dilihat pada Tabel 2.

Dalam Tabel 2 dapat dilihat bahwa LSM sangat berperan dalam rehabilitasi hutan balau (57\%), dimana masyarkat mera- sakan besarnya peranan LSM dalam proses rehabilitasi hutan bakau.

Tabel 2. Peran serta LSM terhadap rehabilitas ekosistem bakau

\begin{tabular}{|c|c|c|c|c|}
\hline $\begin{array}{l}\mathbf{N} \\
\mathbf{0}\end{array}$ & $\begin{array}{c}\text { Peran } \\
\text { LSM }\end{array}$ & Skor & $\begin{array}{c}\text { Jumlah } \\
\text { Responden }\end{array}$ & $\begin{array}{c}\text { Persentase } \\
(\%)\end{array}$ \\
\hline 1 & $\begin{array}{l}\text { Sangat } \\
\text { Berperan }\end{array}$ & 5 & 17 & 57 \\
\hline 2 & Berperan & 4 & 7 & 23 \\
\hline 3 & $\begin{array}{l}\text { Cukup } \\
\text { Berperan }\end{array}$ & 3 & 6 & 20 \\
\hline 4 & $\begin{array}{l}\text { Tidak Terlalu } \\
\text { Berperan }\end{array}$ & 2 & 0 & 0 \\
\hline 5 & $\begin{array}{l}\text { Tidak } \\
\text { Berperan }\end{array}$ & 1 & 0 & 0 \\
\hline & & Total & 30 & 100 \\
\hline
\end{tabular}

Sumber : Diolah dari data primer, Maret 2009.

Berdasarkan hasil analisis korelasi Product Moment didapat hasil 0,344 (pernyataan 2), jika dibandingkan dengan angka kritik tabel korelasi nilai -r maka pernyataan ini tidak memiliki validitas konstruk, artinya tidak memiliki hubungan korelasi dengan pernyataan yang lain.

Hasil wawancara dengan nelayan ternyata, mereka banyak mendapatkan pengetahuan tantang bakau karena keterlibatan dari Yayasan KELOLA yang ada di desa Tiwoho. Yayasan ini juga mengajarkan warga bagaimana cara menanam bakau yang baik, selain itu mereka melakukan pengamatan secara langsung terhadap rehabilitasi ekosistem bakau di desa Tiwoho.

\section{Kelompok Masyarakat}

Usaha pelestarian hutan bakau desa Tiwoho tidak terlepas juga dari peran kelompok masyarakat yang ada di sana. Kelompok masyarakat seperti kelompok tani, kelompok nelayan dan kelompok agama yang ada melibatkan diri dalam usaha pelestarian ekosistem hutan bakau. Kelompok ini juga rutin melakukan penanaman bakau, ada yang dilakukan tiap tiga bulan sekali ada juga yang melakukan tiap bulan sekali. Peran kelompok masyarakat tersaji dalam Tabel 3.

Masyarakat nelayan menilai peran kelompok masyarakat berperan dalam rehabilitasi hutan bakau (47\%), dan hanya 3 responden saja yang memberi jawaban bahwa kelompok masyarakat tidak terlalu berperan.

Berdasarkan hasil analisis korelasi Product Moment didapat hasil 0,683 (pernyataan 3 ), jika dibandingkan dengan angka kritik tabel korelasi nilai -r maka pernya- 
taan ini memiliki validitas konstruk, artinya memiliki hubungan korelasi dengan pernyataan yang lain.

Tabel 3. Peran serta kelompok masyarakat terhadap rehabilitas ekosistem bakau

\begin{tabular}{|c|c|c|c|c|}
\hline No & $\begin{array}{c}\text { Peran } \\
\text { Kelompok } \\
\text { Masyarakat }\end{array}$ & Skor & $\begin{array}{c}\text { Jumlah } \\
\text { Responden }\end{array}$ & $\begin{array}{c}\text { Persentase } \\
(\%)\end{array}$ \\
\hline 1 & $\begin{array}{l}\text { Sangat } \\
\text { Berperan }\end{array}$ & 5 & 6 & 20 \\
\hline 2 & Berperan & 4 & 14 & 47 \\
\hline 3 & $\begin{array}{l}\text { Cukup } \\
\text { Berperan }\end{array}$ & 3 & 7 & 23 \\
\hline 4 & $\begin{array}{l}\text { Tidak Terlalu } \\
\text { Berperan }\end{array}$ & 2 & 3 & 10 \\
\hline 5 & $\begin{array}{l}\text { Tidak } \\
\text { Berperan }\end{array}$ & 1 & 0 & 0 \\
\hline & & Total & 30 & 100 \\
\hline
\end{tabular}

\section{Lembaga Pendidikan}

Lembaga pendidikan memiliki peran untuk mengembangkan bantuan teknis dan teknologi dalam pengelolaan sumberdaya alam dalam hal ini pelertarian ekosestem bakau. Lembaga pendidikan yang ada di desa Tiwoho memberikan kewajiban kepada setiap siswa untuk menanam 1 pohon bakau dan mengawasi bakau tersebut sampai tumbuh. Lembaga ini juga memberikan kurikulum khusus yang disebut muatan lokal yang mengajarkan tentang bakau dan kegunaannya.

Tabel 4. Peran serta lembaga pendidikan terhadap rehabilitas ekosistem bakau

\begin{tabular}{clccc}
\hline No & $\begin{array}{l}\text { Peran } \\
\text { Lembaga } \\
\text { Pendidikan }\end{array}$ & Skor & $\begin{array}{c}\text { Jumlah } \\
\text { Responden }\end{array}$ & $\begin{array}{c}\text { Persentase } \\
\text { (\%) }\end{array}$ \\
\hline 1 & $\begin{array}{l}\text { Sangat } \\
\text { Berperan }\end{array}$ & 5 & 0 & 0 \\
2 & $\begin{array}{l}\text { Berperan } \\
3\end{array}$ & 4 & 19 & 63 \\
& $\begin{array}{l}\text { Cukup } \\
\text { Berperan }\end{array}$ & 3 & 11 & 37 \\
& $\begin{array}{l}\text { Tidak Terlalu } \\
\text { Berperan }\end{array}$ & 2 & 0 & 0 \\
& $\begin{array}{l}\text { Tidak } \\
\text { Berperan }\end{array}$ & 1 & 0 & 0 \\
\hline & & Total & $\mathbf{3 0}$ & $\mathbf{1 0 0}$ \\
\hline
\end{tabular}

Sumber : Diolah dari data primer, Maret 2009

Dalam Tabel 4 terdapat 19 responden memilih Berperan dan sebanyak 11 responden memilih Cukup Berperan. Berdasarkan hasil analisis korelasi Product Moment didapat hasil 0,368 (pernyataan 4), jika dibandingkan dengan angka kritik tabel korelasi nilai -r maka pernyataan ini memiliki validitas konstruk, artinya memiliki hubungan korelasi dengan pernyataan yang lain.

\section{Tingkat Pengetahuan Dan Respon Nelayan \\ 1 Pengetahuan Nelayan Tentang Rehabilitasi Ekosistem Bakau}

Proses rehabilitasi ekosistem bakau di desa Tiwoho telah berlangsung selama 18 tahun dan selama ini masyarakat terutama nelayan telah mengetahui bagaimana cara menanam dan memelihara ekosistem bakau. Pengetahuan tentang bakau banyak diketahui melalui DPTNB (Dewan Pengelola Taman Nasional Bunaken), serta peran swasta yang senantiasa selalu memberikan penyuluhan atau juga pelatihan tentang bakau itu sendiri.

Pengetahuan nelayan dalam rehabilitasi ekosistem bakau tersaji pada Tabel 5 .

Tabel 5. Pengetahuan nelayan terhadap rehabilitas ekosistem bakau

\begin{tabular}{clccc}
\hline No & $\begin{array}{c}\text { Peran } \\
\text { Nelayan }\end{array}$ & Skor & $\begin{array}{c}\text { Jumlah } \\
\text { Responden }\end{array}$ & $\begin{array}{c}\text { Persentase } \\
(\%)\end{array}$ \\
\hline 1 & $\begin{array}{l}\text { Sangat } \\
\text { Berperan }\end{array}$ & 5 & 15 & 50 \\
2 & $\begin{array}{l}\text { Berperan } \\
3\end{array}$ & 4 & 12 & 40 \\
& $\begin{array}{l}\text { Cukup } \\
\text { Berperan }\end{array}$ & 3 & 3 & 10 \\
4 & $\begin{array}{l}\text { Tidak Terlalu } \\
\text { Berperan }\end{array}$ & 2 & 0 & 0 \\
& $\begin{array}{l}\text { Tidak } \\
\text { Berperan }\end{array}$ & 1 & 0 & 0 \\
\hline \multicolumn{1}{c}{ Total } & & $\mathbf{3 0}$ & $\mathbf{1 0 0}$ \\
\hline
\end{tabular}

Sumber : Diolah dari data primer, Maret 2009.

Pada Tabel 5 dapat dilihat ada 15 responden memilih jawaban Sangat Berperan $(50 \%)$ dan 12 responden memilih jawaban Berperan. Berdasarkan hasil analisis korelasi Product Moment didapat hasil 0,355 (pernyataan 5), jika dibandingkan dengan angka kritik tabel korelasi nilai $-r$ maka pernyataan ini tidak memiliki validitas konstruk, artinya tidak memiliki hubungan korelasi dengan pernyataan yang lain.

Dari hasil uraian di atas, nelayan memiliki peran yang cukup baik dalam kegiatan rehabilitasi hutan bakau. Mereka terlibat langsung dalam rehabilitasi bakau tanpa ada paksaan dan bayaran dari pihak manapun, karena mereka berpendapat rehabilitasi bakau bukan hanya untuk dinikmati saat ini, tetapi sebagai warisan untuk anak cucu mereka.

Penanaman dan pemeliharaan bakau di desa Tiwoho tidak mendapatkan perlakuan yang istimewa, seperti: memberi pagar dan pupuk. Penanaman dilakukan dengan cara melihat lokasi yang kosong dan layak ditanami bakau lalu mengambil bibit 
yang tersedia di alam yang dianggap sudah layak untuk dipindahkan kemudian menanam bibit tersebut. Hal ini dikarenakan dari hasil pengamatan dan pelatihan yang mereka dapatkan bahwa bakau akan lebih cepat tumbuh jika dibiarkan tumbuh secara alami.

Dari hasil pengamatan di lapangan, setelah nelayan menanam bakau tidak dibiarkan begitu saja. Bakau yang ditanam, beberapa minggu kemudian akan dimonitor pertumbuhannya, apakah bakau yang mereka tanam ini telah bertumbuh atau mati dan ada juga yang telah terbawa arus saat air pasang. Jika bibit tersebut telah mati atau terbawa arus maka mereka akan mengganti dengan tanaman baru.

\section{Manfaat Rehabilitasi Ekosistem Hutan Bakau}

Ekosistem bakau adalah salah satu ekosistem yang memiliki peran yang sangat penting bagi kehidupan nelayan. Sebagaimana telah dijelaskan pada bagian sebelumnya, ekosistem bakau bermanfaat secara ekologis dan ekonomis. Berdasarkan hasil penelitian, peneliti melihat nelayan desa Tiwoho juga merasakan manfaat dari ekosistem ini. Pada tabel berikut bisa dilihat manfaat apa saja dari ekosistem bakau yang diketahui oleh nelayan desa Tiwoho.

Tabel 6. Manfaat Ekosistem Bakau.

\begin{tabular}{clcc}
\hline No & $\begin{array}{c}\text { Manfaat } \\
\text { Ekosistem Bakau }\end{array}$ & $\begin{array}{c}\text { Jumlah } \\
\text { Responden }\end{array}$ & $\begin{array}{c}\text { Persentase } \\
(\%)\end{array}$ \\
\hline 1 & $\begin{array}{l}\text { Mencari ikan dan } \\
\text { kepiting bakau }\end{array}$ & 10 & 33,33 \\
2 & $\begin{array}{l}\text { Melingungi dari } \\
\text { becana alam }\end{array}$ & 21 & 70,00 \\
3 & $\begin{array}{l}\text { Mencegah pengikisan } \\
\text { di penggiran pantai } \\
\text { Lokasi tambatan } \\
\text { perahu }\end{array}$ & 15 & 50,00 \\
\hline Sumber : Diolah dari data primer, Maret 2009. & 30 & 100,00 \\
\hline
\end{tabular}

Menurut Manik (2003), dalam pemanfaatan setiap sumberdaya alam terjadi suatu proses yang menimbulkan dampak terhadap lingkungan, baik dampak negatif maupun positif. Sebaliknya, kualitas lingkungan juga akan menentukan kelangsungan suatu usaha atau kegiatan. Artinya, lingkungan yang rusak menyebabkan suatu usaha tidak dapat beroprasi. Misalnya, pemanfaatan sumberdaya alam hutan bakau untuk usaha tambak udang. Pembangunan tambak udang seharusnya tidak menebang habis hutan bakau, karena hutan bakau merupakan sabuk hijau pesisir antara lain berfungsi untuk mencegah terjadinya abrasi dan intrusi gelombang air laut.

Dalam uraian sebelumnya masyarakat desa Tiwoho telah merasakan dampak negatif dari pemanfaatan hutan bakau sebagai lahan tambak. Dari hasil pengamatan di lapangan, saat ini masyarakat lebih khususnya nelayan telah merasakan dampak positif dari rehabilitasi bakau. Mereka dapat tidur dengan tenang pada saat musim gelombang tinggi, mereka yakin gelombang tinggi tersebut tidak akan menghanyutkan perahu mereka dan membanjiri kompleks pemukiman. Hal ini dikarenakan gelombang yang datang telah terhalang pepohonan bakau yang ada. Nelayan juga memanfaatkan biota-biota yang hidup di daerah ekosistem hutan bakau apalagi jika tiba musim gelombang tinggi sehingga mereka tidak bisa melaut. Jadi mereka hanya mencari ikan, udang dan kepiting bakau di sekitar bakau. Jadi, menurut nelayan bakau juga menjadi salah satu sumber pendapatan mereka.

\section{KESIMPULAN}

- Hasil penelitian menunjukkan bahwa pemerintah tidak terlalu berperan dalam proses rehabilitasi bakau di desa Tiwoho.

- Yayasan KELOLA yang ada di desa Tiwoho memiliki peran yang besar dalam proses rehabilitasi bakau di desa.

- Usaha pelestarian hutan bakau desa Tiwoho tidak terlepas juga dari peran kelompok masyarakat yang ada.

- Lembaga pendidikan di desa Tiwoho memiliki cukup peran dalam pelestarian ekosistem bakau.

- Nelayan merupakan salah satu pihak yang terkait dalam upaya pelestarian bakau.

- Nelayan terlibat langsung dalam rehabilitasi bakau tanpa ada paksaan dan bayaran, karena kegiatan ini bukan hanya untuk dinikmati saat ini, tetapi sebagai warisan untuk anak cucu mereka.

\section{Saran}

Diharapkan hasil penelitian ini dapat mendorong pemerintah serta instansi terkait untuk lebih berperan serta dalam 
proses rehabilitasi hutan bakau khususnya di desa Tiwoho.

\section{DAFTAR PUSTAKA}

Anonimous, 2005. Departemen Kelautan dan Perikanan. www.dkp.com. Tanggal akses 2-Maret-2007

Kartono, 2000. Pengantar Metodologi Reset Sosial. CV. Mandar Maju. Jakarta.

Manik, K.E.S. 2003. Pengelolaan Lingkungan Hidup. Djambatan, Jakarta.
Singarimbun, M. dan S. Effendi (editor). 1989. Metode Penelitian Survai. Jakarta. LP3S.

Supriharyono, M.S. 2000. Pelestarian dan Pengelolaan Sumberdaya Alam di Wilayah pesisir tropis. PT Gramedia Pustaka Utama. Jakarta.

Subing, Z. 1995. Pengembangan Wilayah Pantai Terpadu dalam Rangka Pembangunan Daerah. Prosiding Seminar V Ekosistem Mangrove. Jember, 3-6 Agustus 1994. 